\title{
The Research on the Interactive Development Mechanism of Urbanization and Service Industry and Their Evolution Rules
}

\author{
Hongqiao Cui* \\ Yatai College of Business Administration, Jilin University of Finance and Economics, Changchun, \\ China \\ *Corresponding author: louisecui@sina.com
}

Keywords: Urbanization, Service Industry

\begin{abstract}
Urbanization drives the structural upgrading of service industry and promotes transformation from self-service to social services by affecting needs, scale and quality of service industry. Meanwhile, service industry is the subsequent power of urbanization and can improve the urban accumulative effect and promote urban infrastructure construction, showing the stronger absorptive role on urban labor. As a result, both of them realize mutual promotion and dynamic development. The structure and layout changes of urban service industry enable the cities with different grades to reveal the standardized service function division, thus urban scale architecture is optimized. Also, urbanization and service industry reveal the regular dynamic evolution features.
\end{abstract}

\section{Introduction}

The previous theoretical research and practice in various countries around the world prove that urbanization and service industry have the interactive relationship ${ }^{[1]}$. Generally speaking, in earlystage development stage of urbanization, the industry has the economic efficiency of scale and drives the accumulation of populations and economic activity space. With the constant increase of service needs, urbanization also provides the good carrier and support for service industry development and promotes the rapid development of service industry. It tends to be gentle by comparing with the industrial development. The production-centered urban functions are gradually replaced by urban functions of the integrated service center. Also, the role of service industry is gradually obvious. The main power that drives urbanization to develop towards the senior stage is also transformed into the service industry from industry ${ }^{[2]}$. How to interact between them and how about the general rules of dynamic evolution between them in the interactive development are main contents in this research.

\section{Function mechanism of urbanization on the service industry}

There is the positive promotion relationship between urbanization and service industry development. Urbanization not only gathers populations in cities, but also gathers the industry in certain area. The double accumulative effect between populations and industry expands social needs 
for life and productive services, so that service industry scale and mode are constantly adjusting, constantly emerging the service industry ${ }^{[3]}$. Therefore, it can be observed that the urbanization level is the important factor affecting needs, development, structural upgrading and scale of service industry.

\subsection{Urbanization affects needs of service industry}

On the one hand, urbanization brings the population accumulation. Production factors and populations form a scale in a specific area. The generation of such a production mode has the strong market needs for production and life services. To begin with, agricultural populations should solve the basic life problem when they go to a city, namely it refers to the need in basic necessities of life. This drives the development of the traditional service industry. At the same time, with the stability of life and gradual improvement on incomes, the demand structure of new urban populations is also changing. Based on the Maslow's hierarchy needs, the higher level needs will be generated under the circumstance of satisfying the survival and safety needs, turning to the spiritual level from substance, so as to drive the increase of cultural education, entertainment relaxation and entrepreneurship needs. In addition, service products provided by service industry have the synchronism of production, consumption and exchange and they can't be stored, thus service needs should form the accumulation. In fact, the characteristics of urbanization exactly conform to various needs of service industry and it is suitable for development of service industry. As a result, service industry is based on the urbanization development and it is improved accompanying with the development of urbanization progress. Increasingly high urbanization level requires that service industry can satisfy more and more needs. Production and life greatly depend on the service industry ${ }^{[4]}$.

\subsection{Urbanization promotes the structural upgrading of service industry}

Populations gather in towns, thus towns are evolved into the developmental base of service industry. Majorities of laborers required by service industry are supplied by towns. Most of values created by service industry actually are provided by towns, so urbanization level develops an important role on the development of service industry. With the constant upgrading of service industry, new service needs with the improvement of urbanization level can be met. The external environment created by urbanization development enables enterprises to enjoy the better public services. For the public services between enterprises, it inevitably will generate the competition, resulting in improving service industry level and inducing the structural upgrading of service industry. Therefore, the structural upgrading evolution of service industry is the consequence promoted by urbanization. Urbanization development naturally drives the optimization upgrading of service structure $^{[5]}$.

\subsection{Urbanization degree affects the scale and quality of service industry}

High or low urbanization degree determines the development level of service industry. The lower urbanization degree slowly gathers populations, thus scale of population accumulation is affected. This inevitably will restrain needs of service industry and need expansion of service industry is also restrained. Furthermore, industry can't form the scale. Besides, it is impossible to rapidly gather populations and fully satisfy talents required by service industry development. Manpower resources will be limited and service industry quality absolutely can't receive the rapid improvement. Meantime, modern service industry needs(such as finance, business and real estate established on the higher social division level) rely on the stronger market system and have the 
stronger external effect. Also, the needs for scale economy are also higher. Thus, if urbanization level is lower and accumulation capacity is poor, this absolutely will affect the scale and quality of modern service industry. To sum up, only the higher urbanization can form the larger development space of service industry. The urbanization development degree has an influence on the scale and quality of service industry development.

\subsection{Urbanization promotes transformation of self-service to social services}

The development from agriculture to industry enables machine production to replace the traditional manual labor. Specialization and collaboration become the important symbols in the industrial age. In the process of marching into the more advanced service industry era from the post-industrial age, urbanization makes specialization and collaboration deepen and improve constantly, thus some industries that belong to the industrial departments are peeled from the industrial system, forming the independent service industry, such as business, transportation industry, information consulting industry, management consulting, communication services and technical identification services. After these industries become the independent industry, their business is rapidly improving, while serving for clients. Relative to previous enterprises or individuals, time and costs of self-service industry are dramatically reduced. The occurrence of such a consequence inevitably promotes transformation of self-service to social services in production and life fields and promotes the improvement on the service industrialization level.

\section{Function mechanism of service industry on urbanization}

The service industry has a difference with agriculture and industry, namely there is no direct substance production, but it provides services for production and life through their labor. Accompanying with the development of productivity, social division is further refined. People have more new needs, while improving their life level. Under the circumstance, service industry is naturally generated and rapidly developed. After completing the industrialization process, replacement of industrialization by service industry development becomes the main driving force for urbanization.

\subsection{Service industry is the subsequent power of urbanization}

Industry is the initial power of urbanization. In the middle and later periods of industrialization development, due to changes of people's life and production mode and arrival of the information age, service industry gradually exceeds the industry and evolves into the important support power of national economy. During the period, service industry needs of productivity and life(consumption) are increased and scale is expanded. This is benefited from the urbanization development. Correspondingly, expansion of urban scale and spatial expansion also benefit from the growth of service industry. Moreover, urban functions and urban radiation strength for surroundings develop an increasingly important role with the development of service industry ${ }^{[6]}$. Based on the experience of developed countries, the correlation between urbanization progress and service industry development is higher than the correlation with the secondary industry development, because service industry in essence provides services. Its coverage area is extremely extensive. The service industry involved often has the higher employment elasticity and absorbs a great number of surplus laborers. The above-mentioned aspects greatly accelerate the urbanization progress. This is inseparable from the driving role of service industry. The countries with the higher urbanization level depend on the rapid development of tertiary industry. 


\subsection{Service industry improves the urban aggregation effect}

Urbanization progress not only gathers populations in towns, but also is the progress to gather economic factors in towns. The reason why towns have the stronger attraction is that towns own the agglomeration economy and scale economic effect and bring the improvement on economic level. The great support of service industry can accelerate the economic agglomeration effect. The service industry always has the helping role of regulation and lubricating economy in the entire process of industrial production, especially for the public services and productive service industry. The good environment created by public services and services for manufacturing industry provided by productive service industry enable the urban agglomeration to develop their own effect. Service industry plays the leading industrial support role in the process of gathering the urban economy. Local economic or urbanization economy can't throw off the basic public services, business services, and educational services ${ }^{[7]}$. Without the support of these service industries, they can't develop the deserved role effect. The self-cohesion and attraction of urban economy is realized through the sound balance operation of service industry.

\subsection{Service industry development directly promotes the urban infrastructure construction}

Service industry gives priority to service provision, instead of non-direct substance production. Therefore, the service industry development needs the favorable external environment and depends on the perfection on transportation, public service industry and road construction or other infrastructures. The experience of western developed capitalist countries proves that towns and industrial enterprises can't be separated from the support of relevant industries and departments, including transportation industry, telecommunication industry, catering industry, and financial insurance industry. In fact, these industries provide a great number of infrastructures and services for urbanization and industrial enterprises, ensuring their rapid development ${ }^{[8]}$. During the process, the most important is that the faster service industry development can greatly promote the urbanization progress, thus equipment speed of urban construction land area and relevant infrastructures also will be faster. Since the reform and opening-up, Chinese service industry has been rapidly developing. This promotes the urban infrastructure development to some extent, so as to drives the urbanization progress of China.

\subsection{Service industry has the stronger absorptive role on urban labor}

Service industry obviously gathers in towns and belongs to the typical urban industry. Majorities of service industries belong to the labor intensive industry and have the stronger employment absorptive capacity, showing the higher employment elasticity. As a matter of fact, urbanization is mainly reflected in the population concentration in towns. The employment posts required by population accumulation should be absorbed by the labor intensive industry, while service industry exactly meets this requirement. The experience research indicates that in town industry, the proportion of employment populations in the secondary industry in employment populations is present in the U-inverse variation, namely it is firstly increasing, and then it remains in 30\%-40\%. With the further development of industrialization, this proportion is present in the declining tendency. The proportion of employment populations of service industry in total employment populations is exactly opposite to the agriculture, showing the continuous rising tendency. In a sense, service industry development has the important role on attracting urban labor and promoting urbanization level development. 


\section{The evolution rules of interactive development between urbanization and service industry}

Table 1. The Dynamic Development Evolution Rules of Urbanization and Service Industry

\begin{tabular}{|c|c|c|c|}
\hline $\begin{array}{l}\text { Urbanization } \\
\text { stages }\end{array}$ & Urban scale structure features & $\begin{array}{l}\begin{array}{l}\text { Service industry structure } \\
\text { features }\end{array} \\
\end{array}$ & $\begin{array}{l}\text { Service industry } \\
\text { layout features }\end{array}$ \\
\hline $\begin{array}{l}\text { Middle and } \\
\text { early periods } \\
\text { of } \\
\text { urbanization( } \\
30 \%-50 \% \text { of } \\
\text { urbanization) }\end{array}$ & $\begin{array}{l}\text { 1. Urban system: regional } \\
\text { populations gather in } \\
\text { metropolis, which increases in } \\
\text { advance. The scale distribution } \\
\text { turns to be average from relative } \\
\text { average. Spatial Gini coefficient } \\
\text { is rising. } \\
\text { 2. Single city: populations } \\
\text { gather in metropolis, middle and } \\
\text { small city centers(downtowns) }\end{array}$ & $\begin{array}{l}\text { 1. Overall structure: service } \\
\text { industry output growth is } \\
\text { slower than the industry. } \\
\text { Employment growth is } \\
\text { equivalent to or faster than the } \\
\text { industry. } \\
2 \text { Internal structure: } \\
\text { circulation service growth } \\
\text { including transportation and } \\
\text { trade is fastest. }\end{array}$ & $\begin{array}{l}\text { 1. Urban system: metropolis is } \\
\text { the center of industry and } \\
\text { service industry. Middle-sized } \\
\text { and small cities give priority to } \\
\text { industry, while service industry } \\
\text { has the lower level. } \\
\text { 2. Single city: service industry } \\
\text { is gathered in metropolis and } \\
\text { middle-sized cities. }\end{array}$ \\
\hline $\begin{array}{l}\text { Middle and } \\
\text { later periods } \\
\text { of } \\
\text { urbanization } \\
(50 \%-70 \%)\end{array}$ & $\begin{array}{l}\text { 1. Urban system: population } \\
\text { aggregation in metropolis starts } \\
\text { slowing down. Population } \\
\text { aggregation in middle-sized } \\
\text { cities is obviously improving. } \\
\text { The urban scale distribution } \\
\text { tends to average. The spatial } \\
\text { Gini coefficient is slightly } \\
\text { reducing. } \\
\text { 2. Single city: populations in } \\
\text { metropolis and middle-sized } \\
\text { cities are expanded to suburbs } \\
\text { from downtowns. Small cities } \\
\text { still have the balance } \\
\text { development. }\end{array}$ & $\begin{array}{l}\text { 1. Overall structure: service } \\
\text { industry output proportion and } \\
\text { employment proportion } \\
\text { exceed the industry and have } \\
\text { the important status in } \\
\text { national economy. } \\
2 \text { Internal structure: } \\
\text { circulation services' growth } \\
\text { speed slows down. Social } \\
\text { services remain the stable } \\
\text { growth. The employment } \\
\text { growth speed is fast and } \\
\text { producers' service growth has } \\
\text { the fastest speed. }\end{array}$ & $\begin{array}{l}\text { 1. Urban system: metropolis } \\
\text { function is transformed to } \\
\text { servicecenter from industry } \\
\text { center and providesvarious } \\
\text { professional services for } \\
\text { middle-sized and small cities. } \\
2 \text {.Single city: service layout of } \\
\text { metropolis and middle-sized } \\
\text { cities is present in the } \\
\text { development feature of } \\
\text { expanding from CBD to } \\
\text { suburbs. The service industry } \\
\text { layout of small cities maintains } \\
\text { concentration. }\end{array}$ \\
\hline $\begin{array}{l}\text { Advanced } \\
\text { development } \\
\text { stage of } \\
\text { urbanization } \\
\text { (above } 70 \% \text { of } \\
\text { urbanization } \\
\text { rate) }\end{array}$ & $\begin{array}{l}\text { 1. Urban system: population } \\
\text { aggregation in small cities } \\
\text { exceeds the metropolis and } \\
\text { middle-sized cities. The urban } \\
\text { scale distribution tends to } \\
\text { average. } \\
\text { 2. Single city: populations in } \\
\text { metropolis and middle-sized } \\
\text { cities go back to downtowns, } \\
\text { showing the re-urbanization } \\
\text { phenomenon. The population } \\
\text { scale and aggregation degree in } \\
\text { small cities are obviously } \\
\text { enhancing. }\end{array}$ & $\begin{array}{l}\text { 1. Overall structure: service } \\
\text { industry output } \begin{array}{r}\text { and } \\
\text { employment have the absolute }\end{array} \\
\text { advantages in national } \\
\text { economy. } \\
\text { 2. Internal structure: } \\
\text { producers' service proportion } \\
\text { is rapidly growing. Circulation } \\
\text { services and social services' } \\
\text { growth speed remains stable. }\end{array}$ & $\begin{array}{l}\text { 1. Urban system: the } \\
\text { knowledge intensive } \\
\text { production services are highly } \\
\text { concentrated in metropolis, so } \\
\text { metropolis becomes the } \\
\text { regional integrated service } \\
\text { center. The industrial } \\
\text { proportion of middle-sized and } \\
\text { small cities is relatively high } \\
\text { and professional degree is } \\
\text { stronger. All cities have the } \\
\text { higher employment proportion } \\
\text { in service industry. } \\
\text { 2. Single city: production } \\
\text { services of metropolis are } \\
\text { highly concentrated in CBD, } \\
\text { while life services are present } \\
\text { in scattered layout. The service } \\
\text { industry spatial layout in } \\
\text { middle-sized and small cities is } \\
\text { relatively balanced. }\end{array}$ \\
\hline
\end{tabular}

Data source: obtained by the author

The rapid development of urbanization develops the important driving role on promoting the regional economic aggregate growth, service industry development and industrial structural upgrading. Meanwhile, service industry development, industrial structural adjustment and 
optimization also accelerate the urbanization progress. Particularly, after completion of industrialization progress, the driver of urbanization is changed into the service industry from industry. The rapid evolution of service industry and constant improvement on the role relationship of urbanization level make them reveal certain evolution rule in the dynamic development process, reflecting in constantly forward process of urbanization. The constant aggregation of populations and elements, constant upgrading of consumption structure and gradually expanded needs in public industry play a great promotion role on the service industry development, thus the overall scale and internal structure reveal the obvious changes. The economic aggregate of services has been improving until it exceeds the industry and becomes the leading industry of national economy. Also, internal structure of service industry is constantly adjustment and proportion of productive service industry continues enhancing, so as to be the important basis to measure the structural optimization of service industry. Accompanying with such changes, the spatial layout of service industry is also optimized. For the sake of gaining the scale advantages and agglomeration economy effect, the productive service industry is concentrated in central business district(CBD). The consumptive service industry and public service industry are based on the distribution characteristics of urban populations, tending to the equilibrium distribution ${ }^{[9][10]}$. The changes of structure and layout in urban service industry make the cities with different grades reflect in the normalized service function division. Also, the urban scale architecture is optimized. Urbanization and service industry reveal the regular dynamic evolution characteristics (see Table 1).

\subsection{The interactive development evolution rules between middle and early periods of urbanization and service industry}

In middle and early periods of urbanization development, the scale distribution of urban system turns to be uneven from relative average, because in the urban system, metropolis is based on the agglomeration effect and development advantages and has the advance growth features, so that regional populations swarm into the metropolis. The improvement on industrial growth speed has the great facilitation on driving the urbanization level. Under the circumstance, service industry output is lower than industrial enterprises. The features of adjusting the service industry structure are shown as follows: the industry output speed is faster than the service industry, while employment growth is equal to or slower than the service industry. As a result, the proportion of service industry in national economy has a small variation. When urbanization is increasingly developing and the level reaches the critical point of middle-early period and middle-later period, the growth sped of employment and output in service industry start showing the blowout growth. The role of service industry in national economy maintains the sustainably stable situation. In terms of the service industry system, the social public service industry relating to the education and sanitation accelerates the growth speed, driving the growth of employment. In terms of the spatial distribution pattern and features of service industry, the metropolis function with the leading role of industry is developed into the orientation of service industry. The scale service industry system with the center of metropolis is developed. Middle-sized and small cities look for more professional services from the large-scale cities. In terms of a single city, the aggregation degree in service industry of metropolis has reached a critical point. The service industry in small and medium-sized cities continues gathering in the downtown.

\subsection{Interactive development evolution rules between middle and later periods of urbanization and service industry}

When urbanization level is transitioned from $50 \%$ to $70 \%$ and it is kept in the middle and later periods of urbanization in the economic development stage, the output proportion and employment 
proportion in service industry will gradually exceed the industry and become the backbone force to enhance the urbanization level. During the period, the urban scale structure tends to balance from imbalance in the stage before. The overall urban development level is slightly rising. As for the entirety of cities, population aggregation speed in large and medium size cities slows down, while middle-sized cities are obviously improving. The urban scale distribution in this stage also starts tending to equalization. The spatial Gini coefficient is slightly decreasing. In terms of the single city, with the expansion of urban scale, urban peripheral services and environment are improving. Furthermore, populations in metropolis and middle-sized cities expand to downtowns from suburbs. Also, the population layout in small cities still reveals the tendency of balance development. From the overall perspective of service industry structure, its proportion in output and employment is higher than the industry, so that its status in national economy is obviously enhancing. In terms of the service industry system, circulation services start the slow growth speed. The growth speed of social services is continuously stable. The employment growth has the fast improvement. Correspondingly, the spatial layout of service industry is adjusting and optimizing with it. With regards to a single city, the distribution pattern of service industry in large and medium-sized cities is reflected in the feature that it is expanded to the suburbs from CBD, while service industry in small cities still maintain the concentrated characteristic.

\subsection{The interactive development evolution rules between advanced development stage of urbanization and service industry}

When urbanization level exceeds 70\%, cities reach the highly developed stage. Service industry creates the majorities of outputs and employments, showing the absolute dominance in the urbanization development process and taking a leading role. During the period, the urban scale structure tends to be more reasonable. Considering the urban system, the gathering speed of populations in small cities exceeds the large and medium-sized cities. Then, urban scale distribution tends to average. In terms of the single city, populations in large and medium-sized cities go back to downtowns, showing the re-urbanization phenomenon. The population agglomeration degree and population scale in small cities are obviously improving. With the promotion of urbanization, service industry structure is increasingly optimizing. Speaking of the overall industry structure, service industry occupies the dominant status in employment and output of national economy. Based on the internal service industry system, producers' service proportion is rapidly increasing. Also, growth speed of circulation services and social services remains stable. In this way, spatial layout of service industry is adjusting with it. As for the urban system, knowledge intensive production services are highly gathered in metropolis, which becomes the regional integrated service center. Besides, industry proportion of middle-sized and small cities has the higher status. Professional degree is also slightly enhancing. The service industry in all cities has the higher proportion to promote employment. From the perspective of a single city, production services in metropolis are highly gathered in CBD, while life services are present in the scattered distribution. The spatial layout of service industry in middle-sized and small cities is relatively balanced.

\section{Conclusion}

By analyzing the mechanism of interactive development between urbanization and service industry, mutual influences of urbanization and service industry structure adjustment, and evolution rules of dynamic development between urbanization and service industry, the author aimed to explore the logical path of interactive development between them. By deeply analyzing the structural evolution features and tendency of service industry in urbanization process, the author further reinforced the cognition of service industry's status, role and necessity in social economy, 
urban economy and urbanization process and summarized structural evaluation mechanism and variation rules of service industry in urbanization process, showing the extremely important significance on enriching the industry structure and regional structure evolution theories, interactive development theories of service industry and urbanization.

\section{Acknowledgements}

The fund project: Planning Project of Social Science Research in Jilin Province Education Department: Research on the Path and Model of Jilin Province's Science and Technology Service Industry Supporting Innovation Driven Development (Serial Number:JJKH20170132SK) ; Schoollevel Project of Jilin University of Finance and Economics: Research on the Path and Countermeasure of Supporting Innovation Driven Development in Science and Technology Service Industry in Jilin Province((Serial Number: 2016P43)

\section{References}

[1] Ari-Pekka Hameri.Production flow analysis-Cases from manufacturing and service industry.International journal of production economics. 2 (2011)

[2] An empirical study of employee loyalty.service quality and firm performance in the service industry .International journal of production economics. 1 (2010)

[3] Bongsug (Kevin) Chae.An evolutionary framework for service innovation: Insights of complexity theory for service science. International journal of production economics .2(2012)

[4] Chen Jian and Jiang Min, the Research on Productive Service Industry and Chinese Urbanization DevelopmentIndustry Collection Mechanism, IER, 6(2012)

[5] Chen Kai, the Influence Factor Analysis of Internal Structure Variation in Chinese Service Industry, EFT, 10 (2006)

[6] Cui Riming and Zhang Zhiming, the Structural Optimization of Service Industry FDI and Chinese Service Industry Structure Optimization: the Mechanism Analysis and Empirical Research, J LU, 1 (2012)

[7] Jiang Xiaojuan and Li Hui, Service Industry and Chinese Economy: Correlation and Potential of Growth Increase, $E R, 1$ (2004)

[8] Lei Yanjun, Discussion on Jiangsu Urbanization and Collaborative Development of Service Industry, MM, 2 (2012)

[9] Zheng Jichang, the Relationship of Chinese Modern Service Industry with Industrialization, Marketization and Urbanization and Its Development Emphasis, Journal of Zhejiang Shuren University, 5 (2009)

[10] Hao Junqing and Cao Mingming, the Relationship Research on the Regional Industry Structure Evolution and Urbanization Development-Based on the Guanzhong Area, Journal of Northwest University(Natural Science Version), 2 (2012) 